\title{
Interpersonal Cues and Consumer Trust in E-commerce
}

\author{
Jens Riegelsberger \\ Department of Computer Science \\ University College London \\ London WC1E 6BT UK \\ +442076793643 \\ jriegels@cs.ucl.ac.uk
}

\begin{abstract}
E-commerce stretches interactions over space and time, and thus requires more trust than traditional shopping. Current approaches to trust-building in e-commerce focus on cognitive trust. Human trust decisions, however, are also based on affective reactions, which can be triggered by interpersonal cues. This research investigates the effect of visual interpersonal cues on users' trust in e-commerce. First results indicate that visual interpersonal cues in the form of photographs have an effect on users' decisionmaking. This effect, however, strongly depends on context variables, as well as individual differences. A further issue under investigation is the potential negative effect of interpersonal cues on task performance. Thus, in a next stage, this research will combine eye-tracking with physiological measurements to investigate effects on task performance and user cost.
\end{abstract}

\section{Keywords}

Trust, E-commerce, Interpersonal Cues, Eye-Tracking.

\section{INTRODUCTION}

Consider shopping in the real world: When a customer enters a shop for the first time, she sees the interior, goods and staff. Visual cues allow her to evaluate the shop's professionalism and competence. Interaction with staff will have further impact on the customer's trust.

As online transactions are stretched over space and time, they are dis-embedded [3]. Dis-embedding is a common phenomenon in modern societies. It makes decisions more complex [4] and increases the need for trust [3]. Hence, designers of e-commerce systems need to design these systems in a way that allows users to build trust (e.g. in B2C e-commerce) but also to encourage trustworthy behaviour among users (e.g. in $\mathrm{C} 2 \mathrm{C}$ e-commerce).

Most work in this area is focused on developing guidelines on 'designing for trust' and assurance mechanisms [7]. Largely, this body of work sees trust as a rational

Copyright is held by the author/owner(s).

CHI 2003, April 5-10, 2003, Ft. Lauderdale, Florida, USA.

ACM 1-58113-630-7/03/0004. expectation - based on signalling good past performance (reputation and ability), interest in future interaction (investment in a relationship), or submission to a control agency (e.g. a trust seal provider). Trust based only on these factors has been described as reliance, or cognitive trust [1]. Human trust decisions, however, encompass cognitive and affective elements. This is captured in Giddens' [3] concept of re-embedding. It states that trust in dis-embedded interactions commonly is maintained through personal, affective trust bonds. Thus, the focus of this research is on hitherto neglected affective trust in ecommerce. Results are likely to be beneficial to practitioners who design e-commerce interfaces (B2C and $\mathrm{C} 2 \mathrm{C})$ but will also provide basic understanding for novel approaches that rely on emotional signalling, such as interactive video assistance or embodied agents.

\section{INTERPERSONAL CUES}

Initial affective trust is built through interpersonal cues that result in immediate affective reactions. Fogg [2] found that photos accompanying on-line articles can increase their credibility, and Olson et al. [5] found that photos of players increased cooperation in social dilemma games played via text-chat. This even holds in situations where interpersonal cues carry no information on the other actor's trustworthiness [3]: Advertising has long relied on imagery of 'friendly faces' to build a positive attitude to products and trust in brands.

\section{RESEARCH RESULTS TO DATE}

An early qualitative study [11] on online shoppers' decision-making confirmed the increased need for trust in e-commerce. Furthermore, shortcomings of approaches purely focused on cognitive trust - such as trust seals were identified. Together with encouraging results from related studies (see previous section) these findings led to focussing this research on affective trust and the effect of visual interpersonal cues. Based on Giddens' concept [3], this approach was termed virtual re-embedding [7, 11].

A first qualitative study on the effect of interpersonal cues, implemented as photos of employees and customers [10], yielded mixed results. Participants' responses ranged from enthusiastic welcome to increased mistrust. Many participants who reacted negatively to the photos claimed that they reduced the usability of the site, as they made it 
harder to identify the functional elements they were looking for. This claim is supported by general web-design guidelines and eye-tracking studies on magazine reading, which found that interpersonal cues - such as eyes on a photograph - attract visual attention. Eye-tracking studies on web browsing, however, found that users largely ignore photos. Within this $\mathrm{PhD}$ research, a preliminary eyetracking study was undertaken to test the effects of photos of faces on visual attention [9]. The photos attracted visual attention the first time a particular page layout was viewed. However, on subsequent views of other pages with the same layout the photos were ignored. No negative effects of the presence of a photo on task performance were found - neither on a first time view nor on subsequent views.

In order to test for an impact on trust, a quantitative experiment investigating the effect of different photos across several sites was undertaken [8]. This study confirmed that photos have an impact on users' decisionmaking under risk. However, whether this impact is positive or negative appears to depend on interactions between site and photo variables. An alarming finding is that the photos seemed to decrease users' ability to correctly differentiate trustworthy from untrustworthy vendors.

\section{METHODOLOGY}

After initial qualitative studies, using Grounded Theory methods, it came clear that trust can not solely be investigated with interviews or questionnaires, because individuals want to appear as rational decision-makers. Trust research that is only based on such methods would underestimate the impact of affective pre-rational elements in decision-making [6]. Thus, to investigate the effect of interpersonal cues on trust and subsequent decisions, methods from experimental economics (which rely on decision-making under financial risk) have been adopted $[6,8]$. In this experimental set-up, participants' pay depends on correctly identifying trustworthy sites. This approach allows analysing the effects of interface elements not only on perceived trustworthiness, but also on the accuracy of participants' trust attribution. This aspect is crucial, as researchers should not only be concerned with elevating trust levels, but enabling correct trust-decisions.

\section{NEXT STEPS}

On a methodological level, the newly introduced decisionbased measure of trust in online vendors needs to be further refined. Results gained with this experimental method need to be shown to hold under field conditions, where real rather than surrogate risks are present [6]. On a substantive level, the interactions between site and photo variables need to be tested further, as they currently are based on explorative data analysis [8]. Potentially negative effects of interpersonal cues on task performance or user cost will be investigated through eye-tracking combined with physiological measures.
To date, this research focussed on visual interpersonal cues implemented as photos. In the next stage, richer implementations, such as pre-recorded video and animated assistants will be investigated.

\section{References}

1. Corritore, C.L., Kracher, B., Wiedenbeck S. (2001). Trust in the online environment. In M.J. Smith et al. (Eds.), Usability Evaluation and Interface Design: Cognitive Engineering, Intelligent Agents and Virtual Reality, 1548-1552. Mahway, NJ: Erlbaum.

2. Fogg, B.J. (2002). Persuasive Technology: Using Computers To Change What We Think and Do. San Francisco: Morgan Kaufman.

3. Giddens, A. (1990). The Consequences of Modernity. Stanford: Stanford University Press.

4. Luhmann, N. (1979). Trust and Power. Cichester: Wiley.

5. Olson, J.S., Zheng, J., Bos, N., Olson, G.M., \& Veinott, E. (2002). Trust without Touch: Jumpstarting LongDistance Trust with Initial Social Activities. Proceedings of CHI2002, 141-146. April 20-25, Minneapolis, MN, US.

6. Riegelsberger, J., Sasse, M. A., \& McCarthy, J. D. (forthcoming). The Researcher's Dilemma: Evaluating Trust in Computer Mediated Communications. International Journal of Human Computer Studies.

7. Riegelsberger, J. \& Sasse, M.A. (forthcoming). Designing E-Commerce Applications for Consumer Trust. In O. Petrovic (Ed.). Trust in the Network Economy. Wien: Springer.

8. Riegelsberger, J., Sasse, M.A. \& McCarthy, J. D. (forthcoming). Shiny Happy People Building Trust? Photos on e-Commerce Websites and Consumer Trust. Proceedings of CHI2003, 5-10 April, Ft. Lauderdale, FL, US.

9. Riegelsberger, J., Sasse, M.A., \& McCarthy, J. D. (2002). Eye-Catcher or Blind Spot? The Effect of Photographs of Faces on E-Commerce Sites. 2nd IFIP Conference on e-commerce, e-business, e-government, 383-398, Oct 7-9, Lisbon, Portugal.

10. Riegelsberger, J. \& Sasse, M.A. (2002). Face it - Photos don't make a Web Site Trustworthy. Extended Abstracts CHI2002, 742-743, April 20-25, Minneapolis, MN, US.

11. Riegelsberger, J. \& Sasse, M. A. (2001). Trustbuilders and Trustbusters: The Role of Trust Cues in Interfaces to e-Commerce Applications. 1st IFIP Conference on ecommerce, e-business, e-government, 17-30, Oct. 3-5, Zurich, Switzerland. 